\title{
Time Folding • Folding Time
}

\section{Lisa Cay Miller}

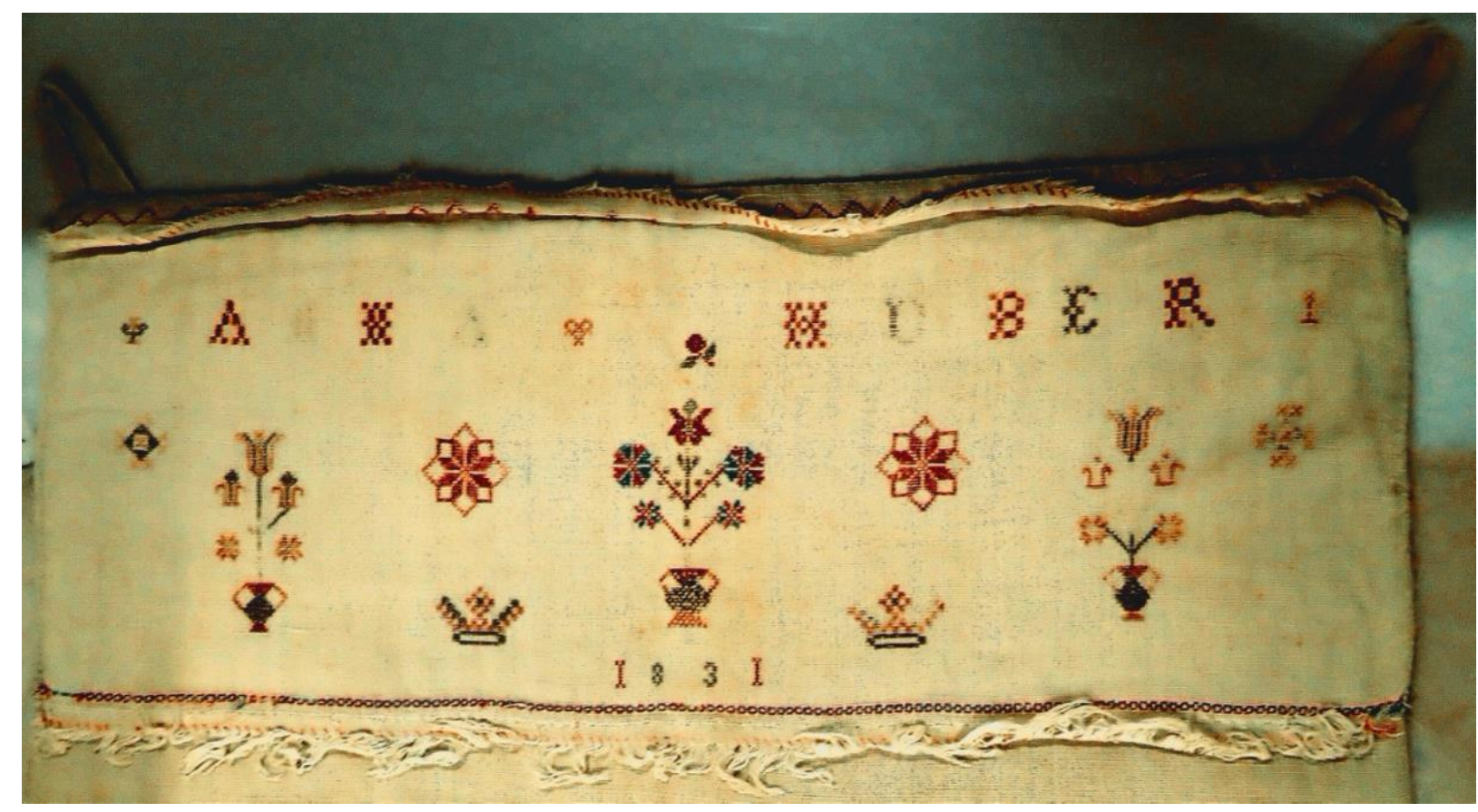

Across the street became the same as across the world. This time changes time. Time borders become biological tickers in Prophetic Time. Calendar Time moves to "Clock time never ... real” (Mendoza 211). Slow fast, peer not-reviewed Journal Time. Conspiracy Time pinging Lightning Time. Fourteen-day cycle Response Time, reflective predictive Before/After/Coming Time, epidemiological models, possibilities shaping orders. Witnessing professional uncertainty as certain, we watch scientists improvise.

Somatic Time, Trauma Time, the sped-up rush of realization dominos across oceans.

Dissociative Time, pushing through confusion fog to stumble act. Martin Amis's Times Arrow moving backward in Denial Time. Chronophobia, panic, depression, anxiety, Subjective Time as a first-time globally shared Psychological Time.

As healing-shifts move towards Ancestral Nature Time. Rising setting. Waxing waning. Growing Time. In nests and first-time flights, from peeps to rasps to full song. Circadian Time overtakes Work Day Time. A Time of Tasks, of making in limitation. We slow. Light behind branches, hand towel stitchings, birds passing, bumblebees burrowing, crows curious, noticed now.

Three Times at Once Time. Improviser/Channeler-Collaborator/Recaller-Composer/Anticipator. In folding time - time folding, improvising Emergent Putting Together Time ${ }^{1}$ to the sounds of colleagues in your ears. Modelling in your mind what might be played by future partners, anticipate remembering of what could be. Future/past/present intention, in spite of the jolt of conditions. Overcoming reluctance to record in isolation, to play alone, to be one's own technician, to balance coping and creating. Finding agency in capabilities and surprise in distant connection. 
Musicians heard not having yet played, Creations appearing later. As Nicole Mitchell states: "And I see through my eyelids and trace the shapes into sonic threads" (231). Multi-directional, listen after, hear before, make today, make next week, and the next. A spatial generosity, forehear, memory hear, ego banished, reactive performance without response. The "musical environment created by the performance" (Bailey 103) not a "separate phenomenon, something really much stranger than the playing itself" (Cardew), but "of" the setting. Engineer architects built host houses of vertically stacked adjacent rooms, spanning cities, countries, continents, to hold our spirituality, our music, layered into films seen and will be seen many-times.

No hand claps, no before/after, introductions, pre/postambles. No public. Paramusical elements removed, the quotidian questioning rituals of the staging of the stage. Firetrucks passing, lawn mowers, neighbours talking and fridges starting burst into private studios. Music in solitude connecting not in real time and space (Bielawa 41), but in alone together temporal rooms.

Curatorial Time, chains of tasks, company-style (Bailey 133) groupings, $6 \times 6,3 \times 12$, mathematical sequencing for fair starts (everyone went first once). Weeks of long-term attention, gracious cooperation, in a risky unknown not done before four-month process. Preparing for what we don't know is coming-curating so big it's like hoarding-except the secured supply is an expression of collegial care for musical mental health. Back and forth, forward and back, forward and forward, back and back, a chain of support, challenges accepted and vulnerability given. Online workshops, lessons, live streams, zoom grids-valuable yet the grief elephant in every room - this was not that. Not a shadow but something new, enthusiastically relayed and suspended. Conditions made this form, not as innovation but as a way through.

Composed Time: two large ensemble pieces, as expressions of time, recorded in parts. "Bsinne," pressing harmonic fields with isolated iterations combined, an immovable branch and changeable light. "Zeitfaltung • Time Folding • Folding Time," improvisers articulating harmonic and melodic material to support never heard solos, the constant cry of the collective, holding everyone who could not be present, movingly, passionately, offering individual threads in cohesion woven by a hand towel five generations old.

In Sequence Time, binding/bonding. Where inhale/exhale passes across borders, connection should also be in Nation State Danger Time, Inequality Revealed Time. These circumstances will never return, yet the apart/connect birth of this form can continue to link musical minds. If the form is adopted, I ask that the actions and values be upheld-cross borders, cross divisions and dividers, uphold egalitarianism and agency. Support each other with care, Across Time, Through Time.

\section{Creative Music Series \#8}

From March to June 2020, during the most intense period of lockdown and the uncertainty of the COVID-19 pandemic, thirty-eight artists collaborated through time folding / folding time. Isolated musicians improvised in their homes in sequence: files moved from musician to engineer, to the next musician, and so on . . Improvisers created in the present, imagined what might come, and responded to what had occurred. Engineers layered the performances in stages, creating architectural master halls from the sonic and visual material of the musicians' locations to create thirty-six films. Two large ensemble films of new works were recorded individually. The passion, generosity, vulnerability, humour, and strength demonstrated in the films document artists transcending separation through collaboration. 


\section{The Improvised Works}

Each group (listed alphabetically) created four trios and two sextets, recorded in different orders. The imagery was created by the musicians; video and sound editing was done by the engineers, Ron Ruiten and Sheldon Zaharko.

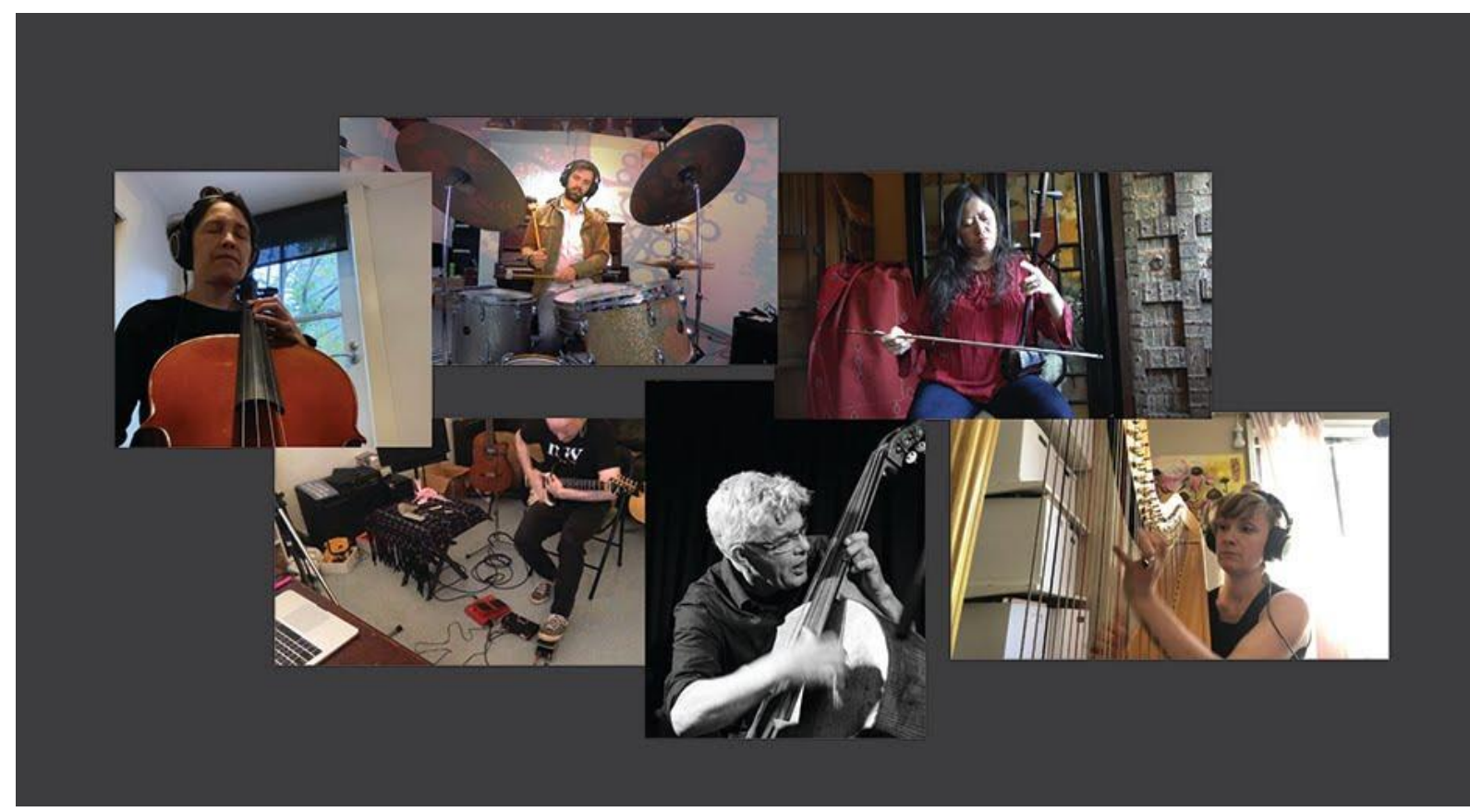

Group 1: Wilbert de Joode (bass), Peggy Lee (cello), Kevin Romain (drums), Elisa Thorn (harp), Lan Tung (erhu/Chinese violin and voice), and Jeff Younger (guitar).

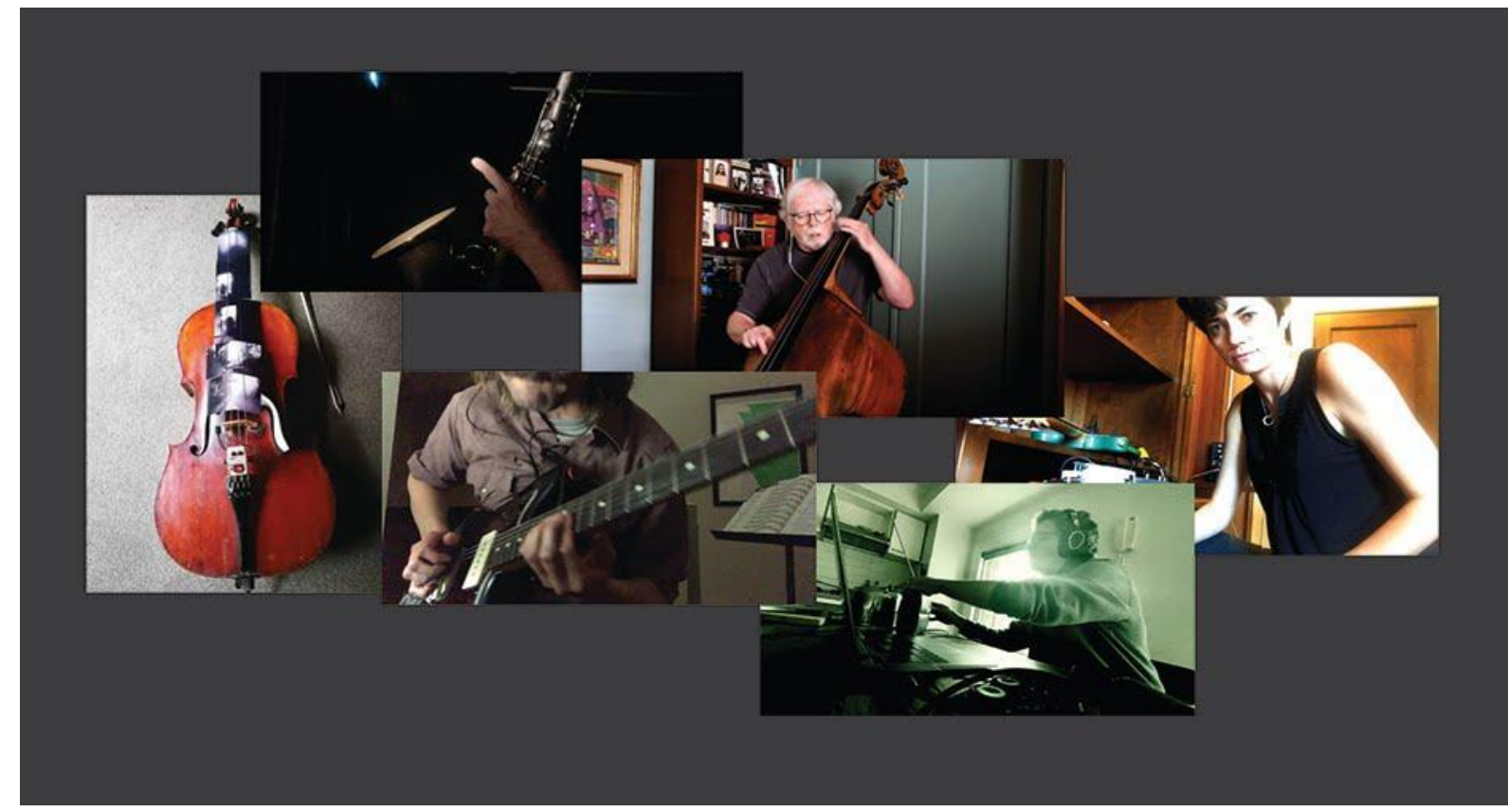

Group 2: Alex Catona (cello), Ava Mendoza (guitar), Ada Rave (saxophone), Clyde Reed (bass), Cole Schmidt (guitar), and Dylan van der Schyff (drums and household objects). 


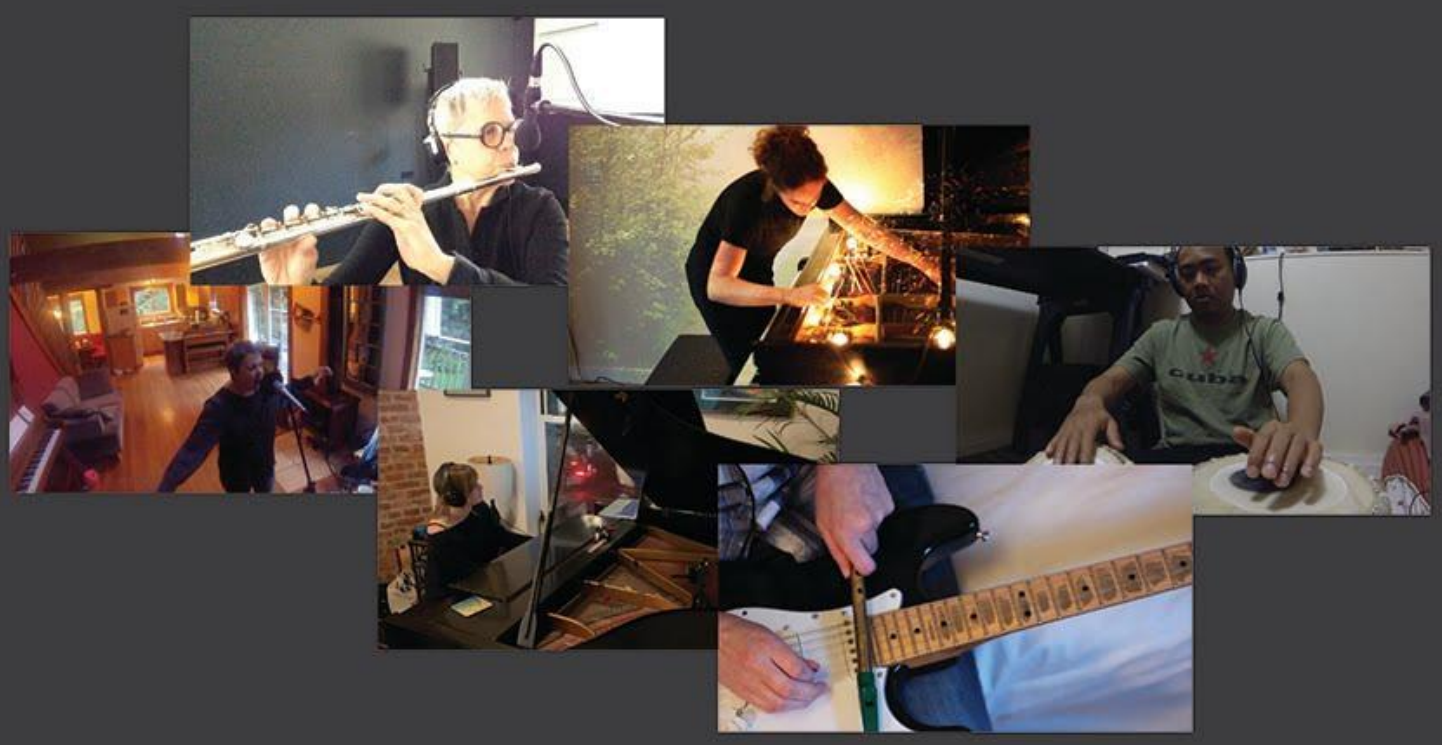

Group 3: Róisín Adams (piano and Wurlitzer), Viviane Houle (voice), Anne La Berge (flute \& kyma system), Balot Ne (drums), Cat Toren (piano), and Chloe Ziner (guitar).

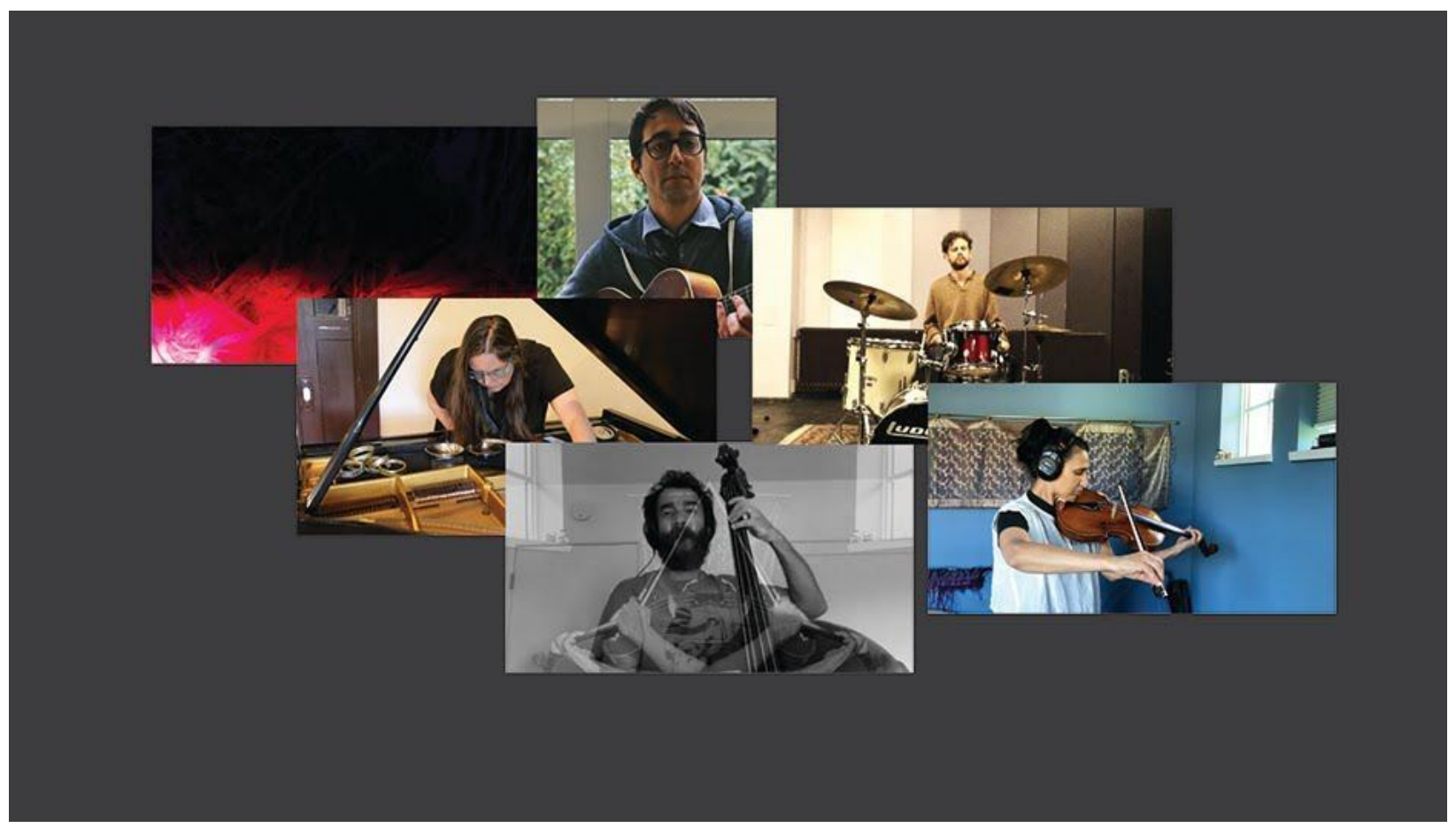

Group 4: Parmela Attariwala (viola), Tommy Babin (bass), Aram Bajakian (guitar), Onno Govaert (drums), Melissa Hubert (flute \& electronics), and Lisa Cay Miller (piano). 


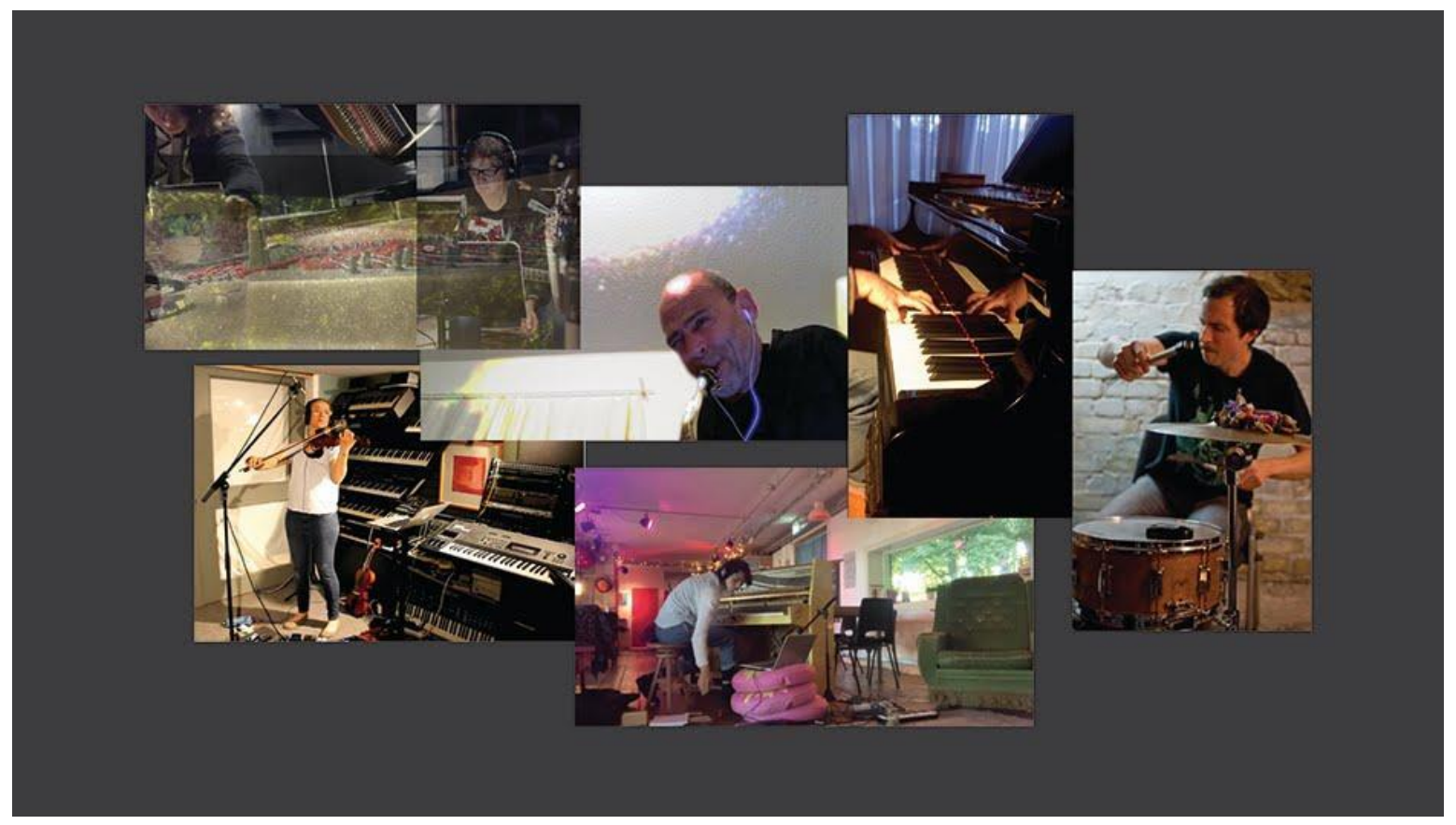

Group 5: Meredith Bates (violin), Ben Brown (household objects), Bruce Freedman (saxophone), Paul Plimley (piano), Ron Samworth (guitar), and Marta Warelis (piano, Rhodes, and synthesizer).

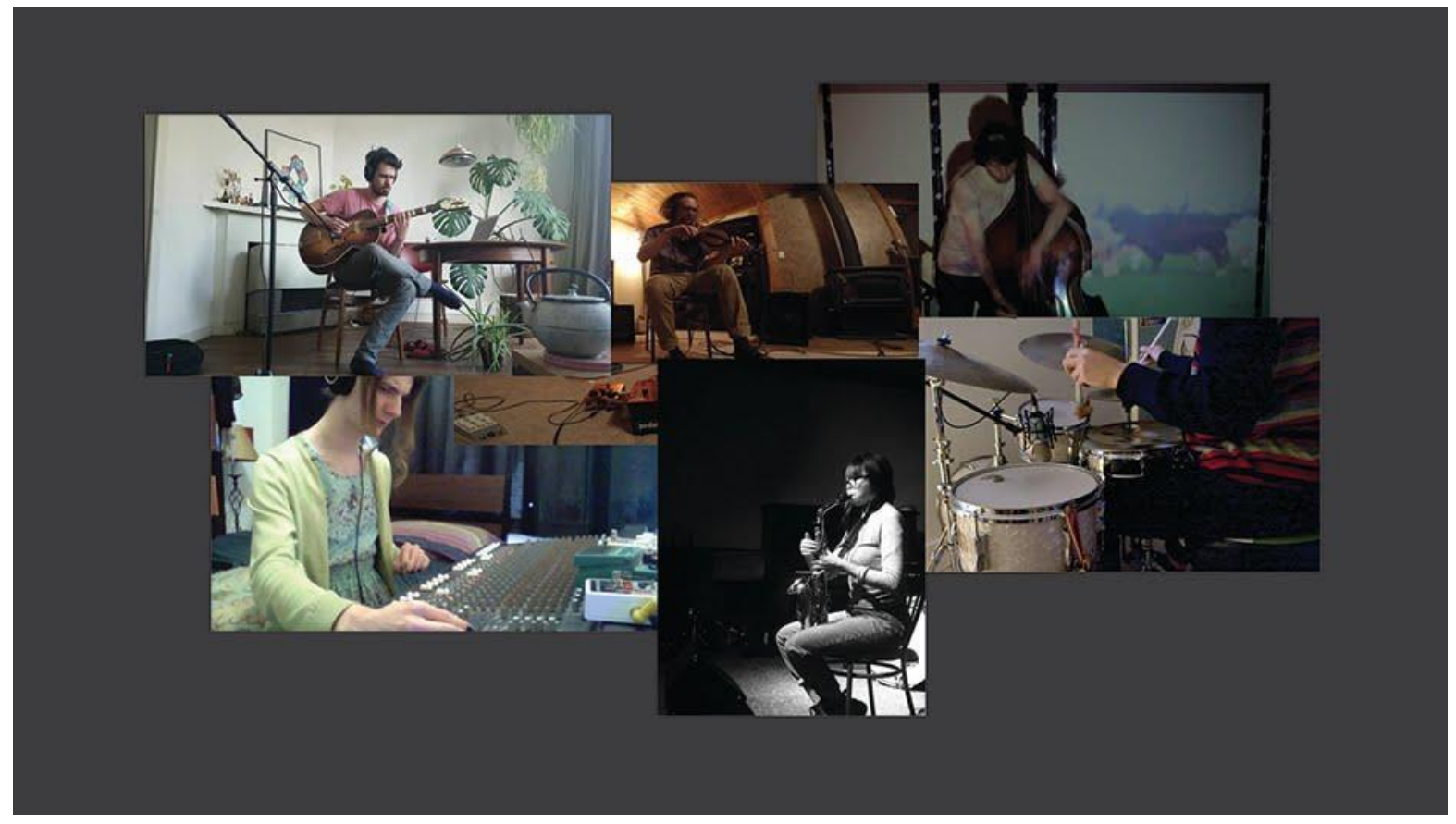

Group 6: Adrian Avendaño (drums), James Meger (bass), Andromeda Monk (no-input mixer), Karen Ng (saxophone), Jasper Stadhouders (guitar), and Joshua Zubot (violin).

Curator and creator of the program: Dr. Lisa Cay Miller Produced by: The New Orchestra Workshop Society (NOW) 


\section{The Composed Works (July 2020)}

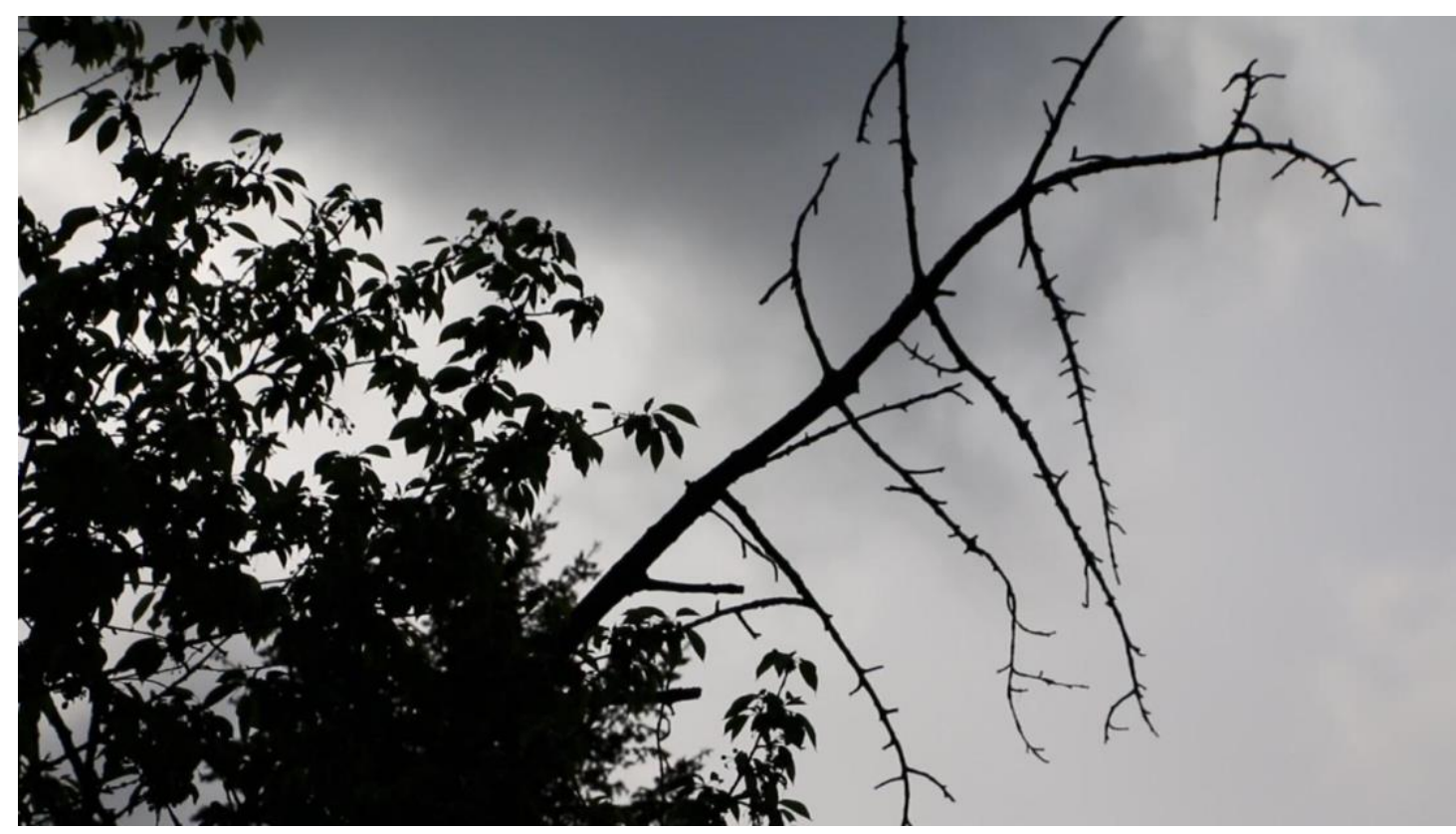

"Bsinne" (9:44)

to consider

to think over

to remember

to recall

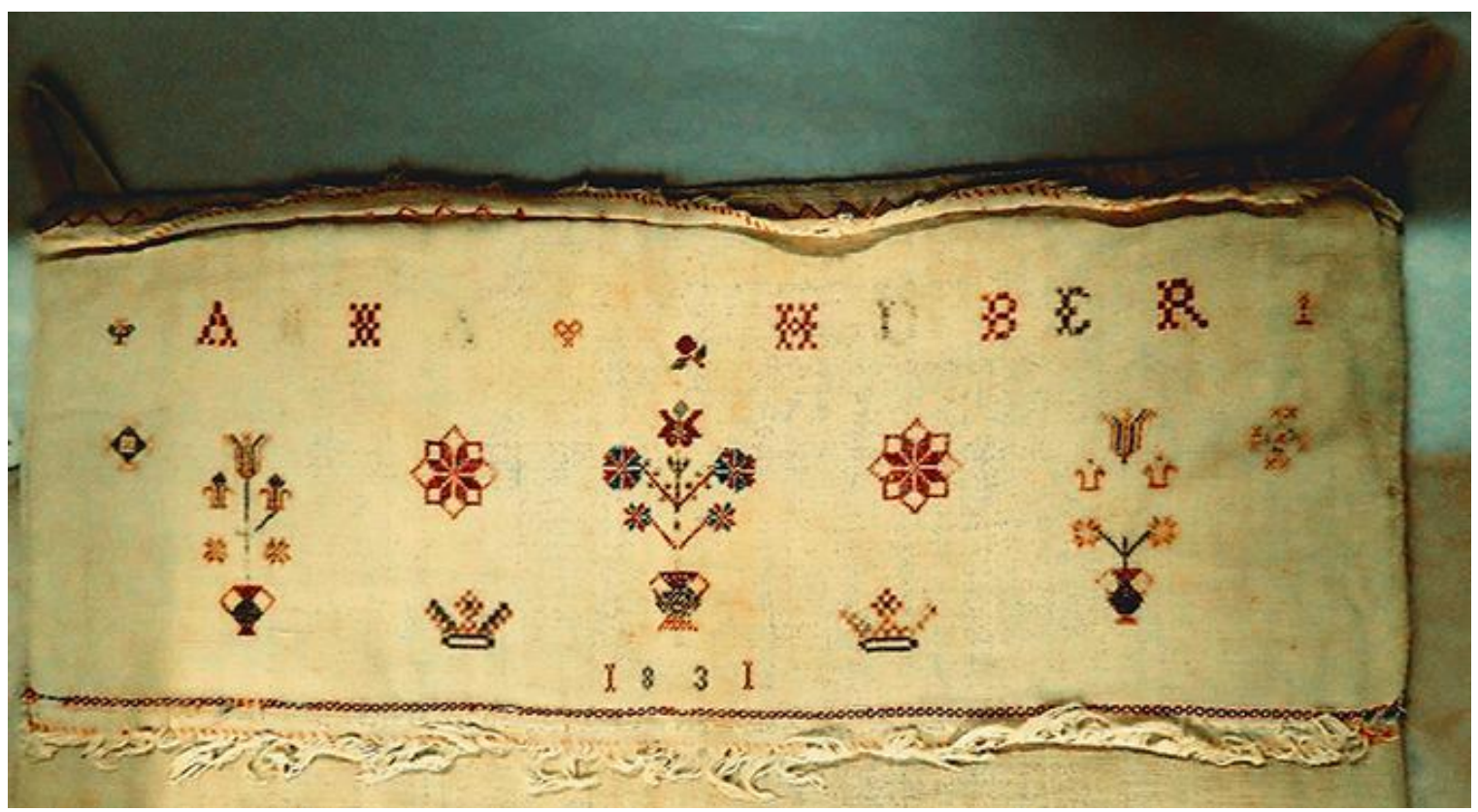

"Zeitfaltung • Time Folding • Folding Time" (17:07) 
Zietfaltung Time Folding • Folding time is inspired by a show towel made by Anna Lehman Huber (Hoover), the composer's great, great, great grandmother. The Handduch, made in 1824 in the Mennonite wedding tradition and style, was likely placed at the center of Anna's home. Mennonite show towels were individual creations, intricate works of embroidery requiring skill and practice.

\section{Credits for the Composed Works}

Composer and Video: Lisa Cay Miller

Sound Engineering and Video editing: Ron Ruiten ("Bsinne"), Sheldon Zaharko ("Zietfaltung · time folding · folding time)

Musicians: Anne La Berge and Melissa Hubert (flute); Karen Ng (clarinet); Andromeda Monk (bass clarinet); Bruce Freedman and Ada Rave (saxophone); Meredith Bates and Joshua Zubot (violin); Parmela Attariwala (viola); Lan Tung (erhu/Chinese violin); Peggy Lee and Alex Catona (cello); Viviane Houle (voice); Elisa Thorn (harp); Jeff Younger, Cole Schmidt, Ava Mendoza, Chloe Ziner, Ron Samworth, and Jasper Stadhouders (guitar); Róisín Adams, Cat Toren, Paul Plimley, Lisa Cay Miller, and Marta Warelis (piano); Wilbert de Joode, Clyde Reed, James Meger, and Tommy Babin (bass); Kevin Romain, Balot Ne, Onno Govaert, Adrian Avendaño and Ben Brown [drums ("Bsinne" only)]

The NOW Society gratefully acknowledges that we make music on the unceded traditional territories of the $x^{w}$ mə日kwəy่əm, Skwxwú7mesh, and səlilwəta? $\$$ Nations.

We collaborate with artists from all over the world.

\section{Notes}

${ }^{1}$ See Barbour for more on the idea of "emergent time."

\section{Works Cited}

Bailey, Derek. Improvisation: Its Nature and Practice in Music. Da Capo, 1992.

Barbour, Julian. "Julian Barbour | The End of Time." YouTube, uploaded by The Institute of Art and Ideas, 4 Aug. 2019, https://youtu.be/GoTeGW2csPk.

Bielawa, Lisa. "Where are We-On Location." Arcana Volume II: Musicians on Music, edited by John Zorn, Hips Road, 2007, pp. 40-49.

Cardew, Cornelius. "Towards an Ethic of Improvisation. Treatise Handbook, Edition Peters, 1971. Available online at https://www.ubu.com/papers/cardew_ethics.html.

Mendoza, Ava. "Self Help: Mendoza vs. Mendoza." Arcana Volume VIII: Musicians on Music, edited by John Zorn, Hips Road, 2017, pp. 207-13.

Mitchell, Nicole. "What was Feared Lost." Arcana Volume VIII: Musicians on Music, edited by John Zorn, Hips Road, 2017, pp. 221-36. 